JURNAL NOMOSLECA

Volume 4 Nomor 1, April 2018

\title{
KOMUNIKASI DIPONEGORO DAN POST-TRUTH ERA PROPAGANDA KLASIK JAWA
}

\author{
Verdy Firmantoro, Anang Sujoko, Antoni \\ Program Studi S2 Ilmu Komunikasi Fakultas Ilmu Sosial dan Ilmu Politik \\ Universitas Brawijaya \\ verdyfirmantorotaa@yahoo.co.id \\ anangsujoko@ub.ac.id \\ ant_ui@yahoo.com
}

\begin{abstract}
This study is manifestation of a non-Western perspective communication research. The dominance of western perspective in communication studies encourages the development of contextual non-Western communication with the source from historical and socio-cultural as a grounded alternative perspective. This study is aims to read the era by examining the historical traces of Prince Diponegoro and post-truth practices that occurred during the Javanese classical propaganda era around the late 18th century and early 19th century. This study uses historiography method through literature review of historical texts related to Prince Diponegoro and social history at that time. The results of this study reveal the fields of production of reality that are influenced by the colonial culture and the practice of de-islamization that separates the local wisdom of the Palace and tradition of the Javanese society. The intersection of Prince Diponegoro's resistance to the amoral values implies the creation of a negative construction of Prince Diponegoro as a rebel figure who only wants to gain power in the land of Java. The clarity of reading historical reality is important in order to avoid a factual twist as a whole of civilization.
\end{abstract}

Keywords: Pangeran Diponegoro, Post-Truth, Colonial Communication, nonWestern Perspective, Identity

\begin{abstract}
Abstrak
Studi ini sebagai manifestasi penelitian komunikasi perspektif non-Western. Dominasi perspektif Barat (Western) dalam studi komunikasi mendorong dikembangkannya komunikasi non-Western yang bersifat kontekstual dengan bersumber dari sejarah dan sosio kultural sebagai perspektif alternatif yang membumi. Penelitian ini bertujuan untuk membaca zaman dengan menelaah jejak historis Pangeran Diponegoro dan praktik post-truth yang terjadi pada masa propaganda klasik Jawa sekitar akhir abad 18 dan awal abad 19. Studi ini menggunakan metode historiografi melalui telaah pustaka atas teks-teks sejarah berkaitan dengan Pangeran Diponegoro dan sejarah sosial di zamannya. Hasil penelitian ini mengungkapkan medanmedan produksi realitas yang dipengaruhi oleh kulturalisasi budaya kolonial dan praktik deislamisasi yang memisahkan kearifan lokal keraton dan tradisi masyarakat Jawa. Persinggungan perlawanan Pangeran Diponegoro atas nilai-nilai amoral berimplikasi penciptaan konstruksi negatif terhadap Pangeran Diponegoro sebagai figur pemberontak yang hanya ingin mencapai kekuasaan di tanah Jawa. Kejernihan membaca realitas historis penting dilakukan agar tidak terjadi pemutar balikkan fakta sebagai keutuhan peradaban.
\end{abstract}

Kata Kunci: Pangeran Diponegoro, Post-Truth, Komunikasi Kolonial, Perspektif nonWestern, Identitas 


\section{PENDAHULUAN}

Sejak tahun 2016 hingga berlangsung saat ini, terdapat diskusi yang sangat populer mempersoalkan praktik kebenaran. Kebenaran dalam situasi ini tidak hanya diperbincangkan dalam ranah faktual semata, melainkan menjurus ke ruang dilematis yang justru mempertanyakan hakikat kebenaran itu sendiri. Produksi kebenaran menjadi paradoks dalam ruang publik. Bahkan Kamus Besar Oxford sangat memerhatikan fenomena ini dan telah memasukkan secara khusus klausul istilah "Post-Truth" dalam rangka melabeli kondisi tersebut. Gleb Tsipursky pada tahun 2017 merilis tulisan bertopik Towards A Post-Lies Future: Fighting "Alternative Facts" and "PostTruth" Politics. Tulisan ini menampilkan anomali-anomali realitas sebagai sebuah entitas yang dikondisikan menjadi benar (truth by design).

Tulisan Tsipursky tidak lepas dengan latar fenomena sensasional abad 21 yang mengantarkan Donald Trump menjadi presiden negara adikuasa Amerika Serikat. Hasil ini cukup membuat masyarakat dunia tercengang bahkan seolah tidak percaya atas kemenangan Donald Trump. Anehnya, media besar sekaliber New York Times dan berbagai lembaga polling dunia melakukan analisa yang tidak akurat dengan menempatkan Hilary Clinton sebagai pemenang. Kondisi ini menjadi salah satu contoh kasus utama yang dinisbatkan mewakili Post-Truth. Post-Truth diartikan sebagai suatu keadaan yang menggambarkan bahwa fakta objektif hanya memiliki dampak yang kecil dalam memengaruhi opini publik, fakta objektif kalah dengan pengaruh emosi dan kepercayaan personal (Mekelberg, 2016).
Kondisi ini mengakibatkan produksi kebenaran bersifat tidak pasti dan sarat subjektivitas yang cenderung tunduk pada rezim kekuasaan.

Hiruk pikuk pertarungan kebenaran tidak saja terjadi di Amerika Serikat, bangsa Indonesia saat ini pun juga mengalami kondisi yang sama. Kebenaran menjadi wilayah artifisial yang setiap pihak mempunyai cara memproduksi kebenarannya masing-masing. Kasus-kasus yang terjadi di ibukota Jakarta, seperti pro kontra terkait penistaan agama yang melibatkan figur gubernur DKI Jakarta Basuki Tcahaya Purnama juga menunjukkan bahwa setiap golongan merasa memiliki kebenaran. Selanjutnya melalui perkembangan teknologi komunikasi, masing-masing golongan mempunyai kuasa dalam memengaruhi opini publik. Kebenaran tidak lagi ditentukan oleh fakta-fakta objektif, tetapi faktor emosional yang bersifat massal akan jauh berpengaruh dalam menggiring opini publik untuk mempercayai suatu kebenaran daripada kebenaran yang lainnya. Jika dikembalikan dalam konsepsi Tsipursky tentang Post-Truth, tentu penjabaran pasca kebenaran tidak lepas dari aspek politis. Komunikasi politik menjadi salah satu pondasi penting dalam mengonstruksi realitas kebenaran. Komunikasi politik sebagai mekanisme untuk mengoordinasi kebenaran agar dapat diterima secara menyeluruh oleh khalayak.

Berbicara komunikasi politik dan post-truth mengarahkan kita pada perbincangan era propaganda klasik Jawa masa Pangeran Diponegoro yang terjadi pada akhir abad 18 sampai awal abad 19. Fenomena post-truth terjadi dengan melibatkan pertarungan kebenaran yang dikonstruksi oleh Pangeran Diponegoro bersama komunitas santri melawan 
konstruksi kebenaran yang diciptakan oleh kolonial. Masing-masing konstruksi kebenaran tersebut memiliki kepentingan dalam rangka melegitimasi pengaruhnya dalam menggiring opini publik. Oleh karena itu, mendiskusikan post-truth yang terjadi dewasa ini tidak dapat dilepaskan dari pengalaman kita dalam kesejarahan Nusantara.

Akar sejarah komunikasi politik Nusantara sangatlah panjang, salah satunya periode Pangeran Diponegoro pada tahun 1785-1855. Kita dapat menemukan fenomena praktik komunikasi politik yang dilakukan Pangeran Diponegoro. Komunikasi politik dilakukan dengan berbagai pihak, termasuk dengan kolonial. Salah satunya, komunikasi politik Pangeran Diponegoro melalui surat tulisan tangan berbahasa Jawa Ngoko yang berisi ungkapan kekecewaan terhadap Jenderal Mayor Cleerens atas pengingkarannya terkait pembebasan Pangeran Diponegoro dari tawanan kolonial Belanda (Sagimun, 1965). Rezim kolonial memiliki otoritas yang besar terhadap penentuan jalur kebenaran yang sesuai dengan kepentingannya dalam rangka melangenggakan kekuasaan (status quo).

Proyeksi post-truth dan komunikasi politik Pangeran Diponegoro terjadi dalam ruang, waktu dan konteks abad 18 akhir sampai abad 19 awal. Jika kita melihat fenomena post-truth dan komunikasi politik di atas abad 19 hingga yang berkembang saat ini, dengan berbagai bentuk dan media yang digunakan, tentu berbeda dengan era Pangeran Diponegoro atau era-era klasik sebelumnya. Ketika belum berkembang teknologi-teknologi komunikasi modern seperti saat ini. Padahal, penggunaan media-media kontemporer saat ini dianggap justru sangat menentukan strategi komunikasi politik dan menciptakan realitas kebenaran. McNair (2003) dalam karyanya An Introduction to Political Communication pada bagian Political in the Age of Mediation, menjelaskan bahwa media sebagai aspek yang krusial dalam mekanisme komunikasi politik.

Beberapa tulisan telah melegitimasi jejak Pangeran Diponegoro sebagai figur yang penting, seperti tulisan Charles van der Plas yang menyebut sosok Pangeran Diponegoro sebagai sumber inspirasi perjuangan kemerdekaan (source of inspiration struggle for independence) dan tulisan Djajeng Pratomo yang menggambarkan figur Pangeran Diponegoro sebagai pahlawan pembebasan masyarakat Indonesia (the hero of liberty of the Indonesian people) (Kroef, 1949). Namun, dualitas konstruksi kebenaran mengarahkan seolah realitas bersifat ganda, di satu sisi bangsa Indonesia menempatkan Pangeran Diponegoro sebagai pahlawan (hero), di sisi lain persilangan persepsi mendudukkan Pangeran Diponegoro sebagai pemberontak (rebel) dalam narasi kolonial.

Membaca kembali komunikasi
politik Pangeran Diponegoro menjadi penting di saat berbagai macam pergeseran terjadi dalam bidang komunikasi politik dan kajian komunikasi politik didominasi perspektif Barat. Kajian komunikasi politik Pangeran Diponegoro dalam konsepsi ini sebagai sarana untuk mengembangkan kajian komunikasi politik dalam perspektif non-Barat (non-Western). Konsepsi posttruth di era Pangeran Diponegoro mengejawantahkan praktik-praktik propaganda sebagai bentuk komunikasi politik yang terjadi di Nusantara. Fenomena post-truth tidak hanya dapat kita temui saat ini saja, melainkan era 
perjuangan masa Pangeran Diponegoro juga mengalami kondisi yang relevan dengan praktik kekinian.

\section{TINJAUAN PUSTAKA}

\section{Post-Truth dan Perubahan Sosial}

\section{Oxford Dictionaries}

mencantumkan post-truth menjadi kosa kata baru untuk memaknai situasi kebenaran sebagai sebuah anomali realitas. Post-truth menjadi konsepsi populer yang merujuk pada pemisahan kebenaran dengan fakta yang objektif. Secara akademis belum banyak ditemukan penggunaan istilah post-truth dalam diskusi ilmiah. Kondisi post-truth saat ini telah mewabah di berbagai bidang, baik politik, komersial atau bisnis juga media (Mekelberg, 2016). Dalam realitas politik, menempatkan fakta-fakta objektif sebagai sebuah narasi tunggal kebenaran dianggap tidak relevan. Selain itu, berkembangnya media sosial juga semakin besar menumbuhkan produksi dan praktik yang mengarah ke post-truth sebagai bentuk terciptanya berita-berita hoax yang sangat jauh dari fakta objektifnya, namun dapat memengaruhi opini publik secara kuat.

Post-truth memiliki keterkaitan dengan perubahan sosial. Perubahan sosial menjadi sebuah keniscayaan dalam praktik kemasyarakatan. Teori-teori komunikasi justru bukanlah sesuatu yang terpisah dengan realitas praktik dalam aspek perubahan sosial di masyarakat, melainkan justru sebagai bagian penting kemasyarakatan tersebut.

"Communication theory is not only about society; it is also in society and contributes to the evolution of the communication practices that constitute society, thereby participating in processes of social change. Communication theory does not arise as a pure scientific invention used to explain society. Rather, communication theory already exists implicitly within cultural practices before it is ever formally written down as theory. Changing ideas about communication have contributed to processes of social change, not only as tools for facilitating change but as essential elements of social change" (Craig, 2013, h. 5-7).

Teori-teori komunikasi dalam keterkaitannya dengan perubahan sosial tidak dapat ditempatkan secara terpisah dengan masyarakat. Komunikasi dalam hal ini bukan hanya sebagai alat konseptual yang menjelaskan masyarakat, melainkan justru berada dalam satu kesatuan entitas masyarakat tersebut. Penekanan perubahan perspektif dalam pemahaman ini menunjukkan bahwa kehadiran komunikasi untuk perubahan sosial tidak cukup di level teknis yang cenderung mekanis, namun perlu melibatkan praktik kultural yang berkontribusi terhadap berlangsungnya perubahan sosial itu sendiri. Bahkan dalam tulisannya A Cultural Approach to Communication, James W. Carey mengutip gagasan John Dewey yang menyebutkan "society exist not only by transmission, by communication, but it may fairly be said to exist in transmission, in communication (Dewey, 1916 dikutip di Carey, 2009, h. 11-12). Berkembangnya perspektif dengan pandangan sosiokultural seperti ini, kemudian mempertanyakan dominasi pandangan awal komunikasi yang dinilai lebih mengarah pada model transmisi yang linier. 
Pergeseran perspektif komunikasi dari model objektif ke model konstruksi menandai dinamika perkembangan kajian komunikasi. "Communication received explicit attention in the context of studies on the adoption and diffusion of innovation that dominated in the field in the 19401970 period. Since then, our theoritical understanding of both innovation and communication has changed markedly" (Leeuwis \& Aarts, 2010, h. 1). Besarnya pengaruh kajian positivistik melalui model objektif dengan riset-riset kuantitatif dan pendekatan difusi inovasi, mengantarkan kajian komunikasi untuk perubahan sosial bersifat top-down. Namun, seiring dengan kritik dan munculnya pendekatanpendekatan alternatif dalam riset komunikasi, merubah arah perspektif komunikasi mulai akhir abad 20 hingga masuk abad 21 sudah berkembang ke arah model konstruksi yang lebih holistik dan kompleks. Perkembangan kajian komunikasi yang mengarah pada model konstruksi menjadi sarana teoritis mengembangkan perspektif non-Western atau Asia. Hal ini seperti yang dikemukakan Robert T. Craig dalam konferensinya di Universitas Indonesia tahun 2010 yang menyarankan adanya upaya dewesternisasi untuk mengembangkan pendekatan Asia dalam studi-studi komunikasi (Craig, 2013).

\section{Komunikasi Politik dalam Perspektif non-Western}

Akar kajian komunikasi politik dapat dipahami dari beberapa literatur pendukung berasal dari Barat yang ditandai dengan lahirnya kajian komunikasi politik terkait isu propaganda oleh Harrold D. Lasswell. Perkembangan kajian komunikasi politik semakin meluas seiring dengan berkembangnya isu-isu politik dalam bidang komunikasi. Merespon kajian komunikasi politik Barat, akar studi perspektif kajian non-Western tidak dapat dilepaskan dari pengaruh Barat termasuk bidang komunikasi politik. Studi komunikasi politik pertama kali muncul di Hongkong dan China pada tahun 1980an yang mengangkat studi tentang interaksi antara media dan negara terutama terkait pengaruh media terhadap formasi opini publik (Chan, 1992a).

Secara khusus para ilmuwan perpektif non-Western menyadari bahwa kajian yang dilahirkan dalam kerangka perspektif Barat dengan non-Western memiliki perbedaan yang mendasar terkait cara pandang dalam memahami fenomena. Perbedaan ini terkait konteks budaya yang relatif berbeda antara Asia atau Afrika (non-Western) dengan Amerika dan Eropa (Western). Bahkan hampir tiga dekade yang lalu, Menon (1988) menyatakan perlunya melakukan pengujian kembali teori-teori Barat dengan melihat konsteks budaya dan tradisi Asia. Kerangka Barat dalam pandangan riset-riset non-Western dianggap terlalu menyederhanakan persoalan dengan melihat mekanisme komunikasi hanya pada tataran yang mekanis, belum memandang secara utuh terkait sisi sosial dan humanistik. Bahkan Chu (1988) menilai riset komunikasi yang dilakukan Barat berfokus pada konsepsi manusia yang cenderung memiliki budaya individu, sehingga mengarahkan pendekatan pada aspek statistik atau kuantitatif dalam mengukur sebuah realitas. Chu memandang bahwa meskipun metodologi yang dilakukan Barat sangat ketat dan sistematis, namun mekanisme riset tersebut dianggap tidak mewakili faktor sosial dan budaya secara 
komprehensif. Hal ini tentu menjadi kriik dalam pendekatan Barat yang mendistorsi budaya tidak menjadi bagian variabel utama dalam menghasilkan rumusan teori maupun riset yang dihasilkannya.

\section{METODE PENELITIAN}

Penelitian ini menggunakan metode historiografi sebagai bagian riset kualitatif. Metode ini mengadopsi dari penelitian dan penulisan dalam studi sejarah. Historiografi adalah metode untuk melakukan penelitian sejarah atau metode untuk mengumpulkan dan menganalisis bukti sejarah (Neuman, 2013: 526). Sejarah sebagai suatu fenomena empiris menjadi objek kajian dalam penelitian lintas disiplin ilmu dan melalui riset ini dapat diidentifikasi temuan-temuan atau data-data masa lalu

Fenomena empiris terkait dengan Pangeran Diponegoro dalam riset ini ditempatkan sebagai sebuah teks sejarah. Melalui kajian teks sejarah tersebut, penelitian ini dibangun menggunakan nalar berpikir dalam perspektif konstruktivis. Meaning are constructed by human beings as they engage with the world they are interpreting (Crotty, 1998, dikutip di Creswell, 2012: 9). Peneliti dalam posisi ini menggunakan data-data sejarah terkait Pangeran Diponegoro dan melakukan analisis historis dalam pendekatan kualitatif. Konstruksi pengetahuan dalam hal ini didasari oleh latar budaya, politik, termasuk pengalaman sosial dalam memaknai sumber kontekstualitas yang terjadi baik di masa lampau dan masa kini. Penelitian ini menggunakan basis data teks-teks sosial seperti Babad Diponegoro sebagai karya klasik Pangeran Diponegoro yang menjadi memori kolektif masa lalu (recollection) dan hasil penelitian para peneliti terkait sejarah berkaitan dengan jejak Pangeran Diponegoro.

\section{HASIL DAN PEMBAHASAN}

\section{Diponegoro dalam Memori Kolektif Nusantara dan Implikasi Post-Truth dalam Propaganda Klasik Jawa}

$$
\text { Belajar mengenai komunikasi }
$$
politik mengangantarkan kita untuk mempelajari kembali salah satu sejarah Nusantara yang mencatat kiprah seorang Pangeran Diponegoro. Pangeran Diponegoro merupakan salah satu pahlawan nasional Indonesia. Sumbangsih dan dedikasinya untuk mengawal perjuangan rakyat dalam perang Jawa menjadikan sosoknya sebagai ikon penting bangsa. Bahkan figur Diponegoro dijuluki sebagai "Singa Jawa". Historisitas yang mencoba menguraikan jejaknya semakin melegitimasi bahwa peran Diponegoro tidak dapat dipandang sebelah mata, terutama menyoal prinsip-prinsip komunikasi politik yang telah dilakukannya.

Melalui buku berjudul Takdir, karya Peter Carey pada tahun 2014 yang menarasikan riwayat Pangeran Diponegoro, kita dapat membaca lebih mendalam sosoknya. Pangeran Diponegoro merupakan anak Sultan Hamengku Buwono III dengan istri selir (garwa ampeyan) yakni Raden Ayu Mangkorowati. Pangeran Diponegoro lahir pada tanggal 11 November 1785, dengan nama kecil Raden Mas Mustahar (Carey, 2014). Darah istana atau keraton mengalir dalam pribadi Diponegoro melalui genealogi biologisnya yang terhubung dengan Sultan Hamengku Buwono II maupun Sultan Hamengku Buwono I. 
Sebelum terjadi peristiwa perang Jawa yang melibatkan aktivitas perlawanan Diponegoro terhadap kolonial, rezim kolonial telah banyak menciptakan friksifriksi di lingkungana keraton. Dalam catatan Carey (2014), orientasi kepentingan pihak kolonial dalam menguasai Jawa dilakukan dengan berbagai cara sebagai manifestasi propaganda menciptakan realitas kebenaran ala kolonial, antara lain:

1. Kulturalisasi budaya populer Barat

2. Komersialisasi Jawa melalui kebijakan "wingewest"

3. Deislamisasi dan praktik penangkapan ulama

Kedatangan bangsa kolonial Belanda di tanah Jawa memengaruhi iklim kebudayaan Jawa terutama yang berpusat di keraton. Kulturalisasi budaya populer bangsa kolonial menjadi tren di kalangan inti pemangku kekuasaan. Pemimpin yang notabene menjadi panutan rakyat justru melakukan praktik-praktik kebudayaan baru yang dianggap tidak wajar dalam sudut padang kepribadian komunitas masyarakat yang berbudaya Jawa. Hegemoni budaya populer Barat semakin mengonstruksi bentuk-bentuk budaya kolonial yang justru ditempatkan sebagai budaya elit. Sementara aspek, komersialisasi dilakukan dengan menerapkan sistem perpajakan dan menyewakan aset-aset lokal kepada pihak kolonial dan asing secara sewenangwenang. Bukan hanya itu, kekuasaan kolonial semakin besar dengan meminggirkan peran-peran ulama tanah Jawa, seperti Kyai Murmo yang ditangkap dan kemudian diasingkan karena dianggap berafiliasi dengan Diponegoro.

\section{Konstruksi Realitas dalam Perspektif Hikayat Tanah Hindia}

Babad Diponegoro menjadi sumber yang penting dalam memahami dan mengeksplorasi lebih lanjut pengetahuan terkait Diponegoro. Di kalangan sejarawan, perpedaan pandangan terjadi dalam melihat babad. Di satu sisi para pakar sejarah menganggap babad sebagai sumber penting dalam rangka merekonstruksi sejarah masa lalu, namun di sisi lain beberapa sejarawan menganggap babad bukan sebagai sumber sejarah. Penulis dalam pandangan ini mengikuti jalur yang menempatkan babad sebagai bagian sumber sejarah yang dapat dimanfaatkan untuk mengkristalisasi pengetahuan lokal sebuah entitas realitas yang terjadi di masa silam. Pandangan ini didukung dengan paparan yang ditulis Nancy K. Florida dalam disertasinya yang mengutip tulisan Zoetmolder, menyebutkan bahwa "in modern usage, the noun babad denotes Javanese accounts of the past, or "histories." The root "babad," a verb which dates from Old Javanese texts, means "to clear (a piece of forest), to open (new land for human settlement)" (Florida, 1990, h. 58). Selain itu, dalam kajian komunikasi pandangan ini juga dikuatkan melalui perspektif non-Western yang melibatkan teks klasik sebagai bahan investigasi melihat konsep-konsep komunikasi masa lampau (Dissanayake, 2003). Maka, pendekatan-pendekatan berbasis budaya yang cukup banyak didapatkan di Asia termasuk Nusantara, mengarahkan babad menjadi salah satu sumber yang penting diperhatikan dan diperlukan pemaknaan secara mendalam untuk membaca teks simbolik tersebut.

Konstruksi negatif terhadap Pangeran Diponegoro sebagai upaya 
pengaburan identitas dilakukan oleh Belanda. Dalam buku klasik Hikajat Tanah Hindia, disebutkan bahwa Pangeran Diponegoro sebagai aktor pemberontak yang hanya ingin mencapai kekuasaan di tanah Jawa.

"Bermoela, maka Pangeran Dipâ Negara menaroeh djoega dendam dalam hatinja, sebab pada sangkanja Gouvernement koerang mengendahkan akan dia, maka terbitlah niatnja dalam hatinja hendak doerhaka. Moela2 iapoen bertapa dan berziarah kapada tempat jang keramat akan membesarkan namanja kapada orang Djawa, sambil bermoeafakat dengan beberapa orang besar dan dengan beberapa orang oelema.

Arkian, maka pada soeatoe hari Pangeran Dipä Negara dengan raajatnja menjerang negeri Djogja, tetapi tiada dapat masoek, sebab itoe dikepoengnja negeri itoe; maka orang Djawa makin lama bertambah banjak berkoempoel dengan Pangeran jang doerhaka. Maka tatkala balatantara Belanda kembali dari pada poelau Selebes, baroe negeri Djogja lepas dari pada moesoeh. Maka sia-sialah GouverneurGeneraal mentjoba mendamaikan Pangeran Dipä Negara, sebab Pangeran itoe hendak naik Soeltan segala orang Islam di poelau Djawa" (Biegman, 1894: 100)

Pernyataan-pernyataan ini berusaha menyudutkan Pangeran Diponegoro. Konstruksi akan kebenaran ditarik ke pihak kolonial yang berusaha memberikan gambaran bahwa Belanda (Gouvernement) menjadi aktor protagonis yang seolah menengahi perselisihan perebutan kekuasaan dalam tubuh keraton. Pihak Belanda memanfaatkan kekacauan suasana yang tengah dialami keraton dengan upaya divide et impera (politik pecah belah). Belanda dalam hal ini memainkan identitas ganda, dengan seolah-olah menjadi penengah (mediator) di satu sisi, tetapi secara strategis mengeksploitasi kekuasaan di tanah Jawa dengan menjadi provokator. Pangeran Diponegoro dinisbatkan sebagai seorang yang durhaka, karena menyerang daerahnya sendiri. Pihak GouverneurGeneraal dinarasikan sebagai pihak yang memiliki kehormatan dengan berupaya mendamaikan Pangeran Diponegoro yang dikonstruksi sebagai orang yang menginginkan tahta kesultanan Yogyakarta.

\section{Komunikasi Kolonial dan Keretakan Identitas Sosial}

Kajian komunikasi ini berkaitan dengan dampak praktik kolonialisasi dalam menciptakan masyarakat baru. Faktor rezim tertentu atau kuasa politik menjadi poin utama dalam memengaruhi terjadinya perubahan sosial. Konstruksi identitas dipengaruhi berbagai faktor yang menyertainya. Konstruksi identitas bersifat dinamis, baik menuju ke arah konformitas maupun mengarah ke arah konstruksi identitas semu. Sebuah identitas dapat dirusak maupun dibangun menjadi intisari kajian dalam penjelasan ini.

Kohesivitas identitas tidak akan mampu bertahan jika praktik rezim yang berkuasa lebih besar dalam melakukan propaganda identitas. Identitas cenderung bersifat top down, yang diprakarsai oleh kelompok-kelompok penguasa. Diaspora identitas memungkinkan terjadi di tengah kerancuan dalam mempertahankan 
identitas lama dan pengaruh kuasa-kuasa rezim peletak dasar-dasar baru dalam mempopulerkan budaya baru sebagai identitas baru yang dianggap "lebih baik". Praktik kolonialisasi yang dilakukan Belanda di zaman Diponegoro dimobilisasi dalam membangun identitas baru yang bersifat Eropasentris. Berbagai wahana menjadi medan pertarungan identitas tersebut.

Adopsi identitas menjadi dilema dalam menciptakan identitas. Perduksian nilai-nilai dan budaya lama digantikan dengan nilai-nilai dan budaya baru hasil adopsi mengarah pada praktik peniadaan identitas lama dan memosisikan identitas baru sebagai subjek peradaban. Peran kolonial mampu meakukan berbagai segregasi di berbagai sektor, baik budaya, politik, spiritual, nasionalisme, dll. Kontestasi konstruksi identitas menjadi medan perjuangan yang mempertemukan antara kelompok dominan dan marjinal. Kelompok dominan melakukan propaganda identitas agar dapat diterima oleh publik secara luas sebagai bentuk legitimasi sosial. Pembentukan identitas yang sampai ke level legitimasi oleh publik ini yang menjadi identitas sosial dalam sebuah entitas masyarakat. Sementara identitas yang tidak diterima atau dikondisikan untuk tidak konformis bagi masyarakat tersebut akan semakin menjadi subkultur yang terus memprivat dan mengecil.

Banyak pandangan mengemukakan bahwa praktik homogenisasi terjadi atas pengaruh global atau kekuasaan ke arah lokal atau publik. Pandangan seperti itu sudah mulai ditinggalkan, seperti yang dikemukakan oleh Racing (1995 dikutip di Dayan, 1998) bahwa kelompok subkultur atau yang selalu diidentikkan di area lokal menjadi sekedar objek saja, namun menurutnya pandangan tersebut tidak dianggap relevan karena yang lokal juga dapat menjadi aktor atau subjek perubahan sosial itu sendiri. Otonomi dan komunalitas sosial dapat terbentuk diakibatkan oleh ketidakadilan yang dialami oleh masyarakat di masa Diponegoro. Berbagai individu dan kelompok membangun kekuatan jaringan publik yang kemudian melakukan perlawanan atas kolonialisai tersebut. Upaya rekonstruksi identitas yang terancam tergerus dilakukan oleh Diponegoro dengan berbagai hal, seperti pemebentukan komunitas santri, literasi dan dakwah keagamaan, maupun penggunaan media lain dalam membangkitkan kesadaran identitas bersama "kekitaan" termasuk memainkan peran sentral dalam konstelasi gerakan semesta dalam bentuk perang Jawa atau perang Diponegoro.

Praktik divide et impera justru dilakukan kolonial dalam rangka membelah kesatuan identitas yang terbangun di Jawa. Propaganda ini berhasil dengan membesarkan kekuasaan Belanda atas Jawa. Kolonialisasi dilakukan dari pusat keraton sampai berdampak ke masyarakat luas. Keraton yang dianggap sebagai pusat peradaban justru dikooptasi dengan prtaktik-raktik budaya amoral dan melepas kuasa budayanya sendiri untuk digantikan dengan budaya asing yang dianggap lebih superior. Kulturalisasi berdampak pada pembentukan identitas sosial.

Proses pembentukan identitas melewati beberapa proses. Dayan (1998) menyebutkan identitas sebagai proses yang melampui tiga hal, yakni produksi, konfrontasi dan adopsi. Upaya memertahankan identitas akan mengalami pasang surut. Representasi identitas sosial 
menjadi bagian realitas masyarakat dengan mengetahui siapa dirinya dan ke mana orientasi yang dimilikinya. Praktik kolonialisasi mampu menggusur budaya dan nilai yang telah hidup ajeg dalam masyarakat menjadi bersifat kebaratbaratan, seperti bangga mengenakan pakaian-pakaian Belanda yang dianggap lebih terhormat daripada pakaian Jawa, minum-minuman keras sebagai budaya komunal, lokalisasi dan pengembangan praktik prostitusi. Menurut Dayyan (1998) komunitas minoritas cenderung dikontrol oleh mayoritas dan mengikuti segala konsekuensi yang terjadi di dalamnya. Identitas sebagai sebuah proses pengadopsian telah menjadi budaya baru sebagai identitas sosial di masyarakat Jawa era klasik dulu. Budaya-budaya Barat berhasil diinternalisasi menjadi identitas privat dan sampai akhirnya menjadi identitas sosial. Perubahan sosial terjadi akibat praktik: kulturalisasi budaya populer Barat/ kolonial, komersialisasi Jawa melalui kebijakan "wingewest", maupun deislamisasi dan praktik penangkapan ulama yang menjauhkan keraton berpisah dengan nilai-nilai adiluhungnya.

Berikut adalah beberapa dokumentasi historis yang menjadi identitas sosial Jawa klasik era Diponegoro dengan menggunakan atribut-atribut dan perangai Belanda, seperti:
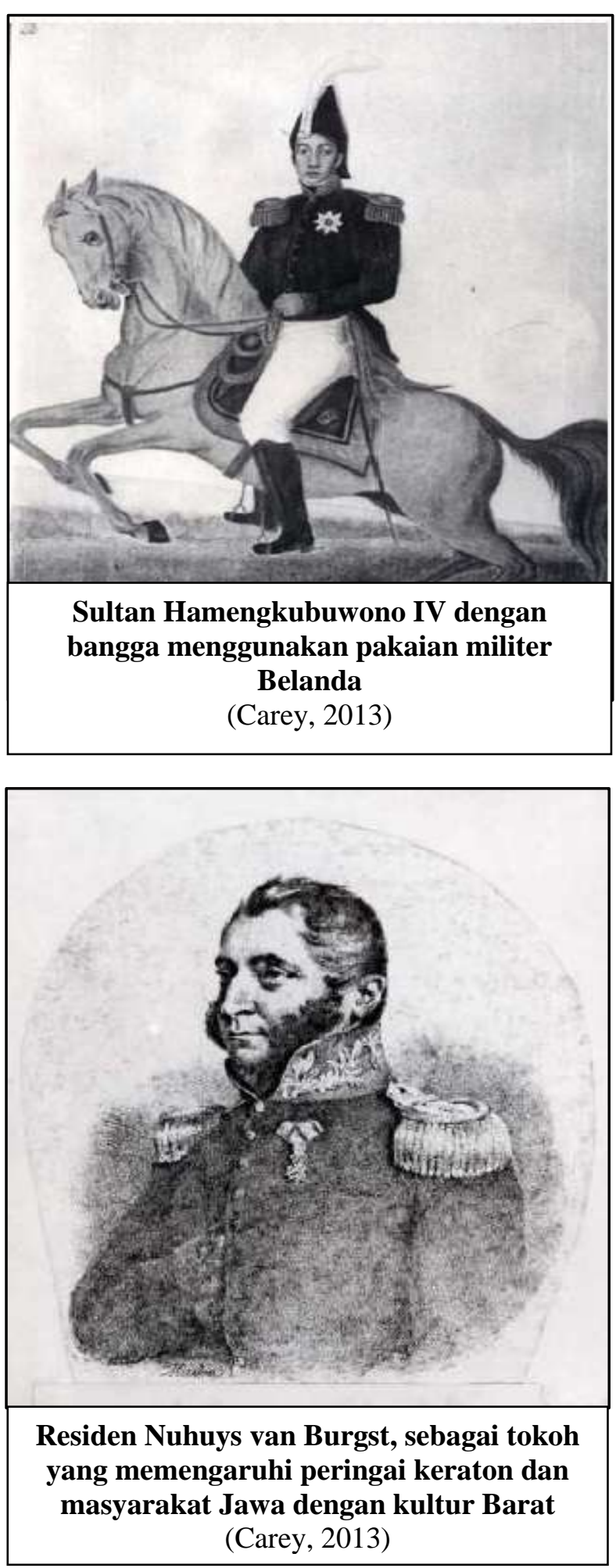
Melalui berbagai pengaruh dari Belanda, berbagai budaya baru khas kolonial masuk dan menjadi identitas bersama di kalangan keraton. Tercerabutnya akar keraton dari dimensi budaya lokalnya, melambangkan penggerusan budaya tradisional oleh budaya populer yang sebenarnya sebagai budaya asing yang baru masuk. Konstruksi identitas sosial tidak terjadi begitu saja melainkan melibatkan mekanisme politik dan pertarungan ideologi dalam memengaruhi atmosfer kehidupan masyarakat menjadi bagian pendukung komunitas kolonial. Sementara itu, catatan historis atas terjadinya perang Diponegoro sebagai bentuk upaya rekonstruksi identitas yang menjadi penanda perubahan sosial.

\section{PENUTUP}

\section{Simpulan dan Saran}

Historisitas membaca jejak Nusantara memproyeksikan figur-figur luhur sebagai memori kolektif bangsa termasuk Pangeran Diponegoro. Masa kolonial menjadi salah satu momen bersejarah saat narasi identitas menjadi medan kontestasi antara lokal di satu sisi dan kolonial di sisi lain. Post-truth dalam sejarah Jawa telah memberi catatan penting yang berkaitan dengan relasi ideologis praktik propaganda kolonial yang menghegemoni konstruksi kultural masyarakat Jawa. Konstruksi realitas relatif sulit tampil secara alamiah terutama berkaitan dengan sejarah kekuasaan, karena kecenderungan kepentingan oposisional yang selalu menyertai dan bersifat kontradiktif. Melalui tragedi historis, setiap figur perubahan memungkinkan bertindak ganda, menjadi pahlawan sekaligus di saat yang sama dikonstruksi sebagai pengkhianat. Praktik komunikasi menjadi wahana pertarungan identitas. Rezim kolonial menunjukkan kuasa-kuasa segregasional yang mencerabut tatanan identitas lama yang disubkulturkan dengan tatanan populer yang ahistoris. Komunikasi Diponegoro menjadi refleksi kultural melawan propaganda kolonial yang berkonsekuensi menstimulus retaknya identitas sosial.

Penjernihan secara edukatif perlu dilakukan dalam membaca sejarah sebagai praktik komunikasi peradaban. Komunikasi menjembatani khasanah pengetahuan di masa silam agar dapat terhubung dengan pemikiran-pemikiran manusia modern di masa kini. Pelestarian terhadap memori-memori kolektif kebangsaan memberikan pembelajaran kritis yang dalam konteks ini menunjukkan praktik propaganda sebagai kontestasi wacana kebenaran. Melalui telaah ini mendorong untuk dilakukan penelitianpenelitian konstruktif melalui pendekatan sejarah (communication history) khususnya dan komunikasi dalam perspektif nonWestern pada umumnya sebagai perspektif alternatif mengembangkan komunikasi keindonesiaan atau kenusantaraan.

\section{DAFTAR PUSTAKA}

Biegman, G. J. F. Hikajat Tanah Hindia. Batawi: Kon Instituut Taal-Land En xxxxxx VolkenkundeNed Indie.

Carey, J. W. 2009. A Cultural Approach to Communication. Journal of Communication and Media Studies Collection, 11-28.

Carey, P. 2013. Menghadapi Zaman Edan: Etnisitas \& Globalisasi di Jawa Tengah-Selatan pada Era Gelombang Globalisasi Kedua 
(1750-150), Teladan Pangeran Diponegoro (1785-1855): Suatu Warisan dan Suatu Tantangan bagi Bangsa Indonesia. Summer School Lecture for the ICRS, Yogyakarta. 26 Juni 2013.

Carey, P. 2014. Takdir - Riwayat Pangeran Diponegoro. Jakarta: Kompas Gramedia.

Craig, R. T. 2013. Communication Theory and Social Change. Journal of Communication \& Social Change, 1 (1), 5-18.

Chan, J. M. 1992a. Communication research in Hong Kong: Problematics, Discoveries and Directions. Asian Journal of Communication, 2, 134-167.

Chu, G. C. 1988. In search of an Asian perspective of communication theory. Dalam W. Disssanayake (Ed). Communication Theory: The Asian Perspective (h. 204-210). Singapura: AMIC.

Creswell, J. W. 2012. Research Design: Qualitative, Quantitative, And Mixed Methods Approaches Second Edition. New York: Sage Publication.

Dayan, D. 1998. Particularistic Media and Diasporic Communications. In $\mathrm{T}$. Liebes and J. Curran (Ed). Media, Ritual and Identity (h. 103-113). London: Routledge.

Dipanegara, P. 1832. Babad Dipanegara. Penerjemah: Gunawan, Apriyanto, Nana, Yeri, Isidora. Yogyakarta: NARASI.

Dissanayake, W. 2003. Asian Approaches to Human Communication: Retrospect and Prospect. Intercultural Communication Studies, XII (4): 17-37.
Florida. 1990. Writing The Past, Inscribing The Future: Exile And Prophecy In An Historical Text Of NineteenthCentury Java. Dissertation. Cornell University.

Kroef, J.M. 1949. Prince Diponegoro: Progenitor of Indonesian Nationalism. Journal of The Far Eastern Quarterly, 8 (4), 424-450.

McNair, Brian. 2003. An Introduction to Political Communication, ed. 3rd, London: Routledge.

Mekelberg, Y. 2016. Is Post-Truth The Only Truth Left In Public Life?. Journal of Al Arabiya.

Neuman, W. L. 2013. Metodologi Penelitian Sosial: Pendekatan Kualitatif dan Kuantitatif Edisi 7. Penerjemah: Edina T. Sofia. Jakarta: Indeks.

Sagimun, M. D. 1965. Pahlawan Dipanegara Berdjuang. Jakarta: Gunung Agung.

Tsipursky, G. 2017. Towards A Post-Lies Future:Fighting "Alternative Facts" And "Post-Truth". Journal of The Humanist, 77 (2), 12-15. 